Cheng, Meng-Hsiung; Liao, Jyh-Jong; Pan, Yii-Wen; Li, G.-W.; Huang, Ming-Wan; Lo, W.-H.; Hsu, S.-T.

\title{
Soft-Rock Scouring Processes Downstream of Weirs
}

Verfügbar unter / Available at:

https://hdl.handle.net/20.500.11970/100289

Vorgeschlagene Zitierweise / Suggested citation:

Cheng, Meng-Hsiung; Liao, Jyh-Jong; Pan, Yii-Wen; Li, G.-W.; Huang, Ming-Wan; Lo, W.-H.; Hsu, S.-T. (2010): Soft-Rock Scouring Processes Downstream of Weirs. In: Burns, Susan E.; Bhatia, Shobha K.; Avila, Catherine M. C.; Hunt, Beatrice E. (Hg.): Proceedings 5th International Conference on Scour and Erosion (ICSE-5), November 7-10, 2010, San Francisco, USA. Reston, Va.: American Society of Civil Engineers. S. 724-733. 


\title{
Soft-Rock Scouring Processes Downstream of Weirs
}

\author{
Cheng, M.-H. ${ }^{1,2}$, Liao, J.-J. ${ }^{1}$, Pan, Y.-W. ${ }^{1}$, \\ Li, G.-W. ${ }^{1}$, Huang, M.-W. ${ }^{1}$, Lo, W.-H. ${ }^{1}$, Hsu, S.-T. ${ }^{2}$
}

${ }^{1}$ Department of Civil Engineering, National Chiao-Tung University, 1001 Ta-Hsueh
Rd., Hsinchu 30050, Taiwan; email: jjliao@mail.nctu.edu.tw
${ }^{2}$ Water Resources Agency, Ministry of Economic Affairs, 1340, Jhong-Jheng Rd.,
Wufong Township, Taichung County 413, Taiwan; email: chengms@wrap.gov.tw

\section{ABSTRACT}

Diversion weirs are typically constructed to elevate river water levels and thereby increase water supplies. Most riverbeds in the western foothills of Taiwan are composed of soft sedimentary rocks covered with an armor layer of varying thickness. Due to the low rock strength and head fall caused by weirs, rapid scouring downstream of the weir often occurs once the armor layer is worn away. To estimate scour depth and mitigate its damage to weir foundations, scouring processes must be identified correctly. Because of different mechanical behaviors and the water-jet conditions, scouring processes downstream of a weir on soft rock may not be that same as those assumed by existing models. Analytical results from a series of studies of scouring downstream of weirs on soft rock indicate that the shape of a scour hole on soft rock differs markedly from that of a scour hole on hard rock. This study identified three basic scouring processes downstream of weirs, namely, (1) plucking, (2) uniform incision, and (3) trenching incision. The suitability of existing approaches for calculating the depth of a scour hole on soft rock were also assessed.

Keywords: scouring processes; soft rock; weir; scour hole

\section{INTRODUCTION}

Diversion weirs were typically constructed across rivers in Taiwan to elevate the river level to increase water supply. These weirs alter the nearby river slope and result in loss of the armor layer; the rock mass downstream of the weirs is then exposed. Also, the extra flow energy due to the head fall enhances rock cracking or breakage, and a scour hole may then develop gradually. Eventually, scouring may reach an extent that weir stability is endangered. 
The common erosion mechanisms in a rock bed can be classified as plucking, abrasion, and cavitation. The major mechanism depends on substrate lithology, joint spacing, fractures, and bedding planes. Plucking is the dominant scouring mechanism when rocks are well jointed on a sub-meter scale. Abrasion is the result of wearing by a suspended load or saltating bedload. Cavitation occurs when a water environment has a high-speed vortex (Whipple 2000).

Many empirical or semi-empirical formulae for estimating the depth of a scour hole in a granular riverbed were developed using experimental data in the laboratory or field (e.g., Schoklitsch, 1932). The parameters used in those formulae may include grain size, flow rate, flow velocity, flow impact angle, and fall height. Among these parameters, grain size is the only material parameter that characterizes the geo-material of a riverbed.

To estimate the depth of scour holes in rocks, many studies directly adopted approaches used for granular materials. The bed material is simply taken as a cohesionless granular material when estimating the depth of a scour hole in a rock bed. Such approaches assume the rock mass is broken and all rock blocks are fully separated. Similar to cases for granular materials, the shape of a scour hole downstream is a slope with a constant angle related to the friction angle of the material. The depth of a scour hole can be calculated using the critical incipient shear stress law or the principal of conservation (Fahlbusch, 1994; Bormann, 1991; Liu, 2005). However, such approaches cannot closely predict the scouring potential of rock materials or rock masses.

Evaluating the scouring process for a rock mass is more complex than that for granular materials. Annandale developed a geo-mechanical index method; an erodibility index was utilized to quantify relative rock resistance to scouring (Annandale 1995). The erodibility index accounts for such factors as unconfined compressive strength, block size, shear strength of discontinuity, and the orientation of the discontinuities relative to flow. With the correlation between threshold stream power and the erodibility index, one can evaluate scouring susceptibility for a specific site as long as stream power at that site can be calculated from unit flow rate and fall height. Annandale (Annandale 2006) also utilized this method to estimate ultimate scour depth. With height of the tail water as constant, erosive power decreases as water depth increases because of energy dissipation. The erodibility index may vary (often increases) as water depth increases. Consequently, at a certain 
depth, erosive power cannot overcome rock resistance to erosion; thus, scour depth can be estimated accordingly.

The fluctuating dynamic jet pressure and its propagation into rock joints have been discussed since the 1960s. Bollaert and Schleiss (2003) summarized the physical-mechanical processes of scouring as the following modules: (1) aerated jet impact; (2) jet diffusion in a plunge pool; (3) fluctuating dynamic pressures at the water-rock interface; (4) propagation of these pressures into underlying rock joints and hydraulic fracturing of the rock; (5) dynamic uplift of single rock blocks; and, (6) downstream mounding of material. They adopted two-dimensional jet diffusion theory to estimate the fluctuating dynamic pressure on rock surfaces, and the ratio of pressure amplification in joints. Scour depth can be estimated based on the force equilibrium of rock blocks. They used this approach to estimate scour depth and apron concrete thickness in plunge pools, where bedrocks are hard and jointed (Bollaert 2003).

Generally, most approaches for estimating scour depth were developed for plunge pools downstream of dams. In this case, the magnitude of jet energy depends on dam height, and energy dissipation follows two-dimensional diffusion theory. However, a diversion weir is typically submerged during flooding because the fall height of weirs is limited. Compared with high dams, the jet impinges a relatively small angle incline relative to the horizontal plane. The energy dissipation mechanism in front of a diversion weir may differ from that in the case of a jet falling from a spillway. Lin (2001) conducted a series of flume tests and characterized the formation of a scour hole caused by a low hydraulic jump. The depth and shape of the developed scour hole depend on flow conditions and tail water depth.

Most riverbeds in the western foothills of Taiwan are composed of soft sedimentary rocks, such as sandstone, siltstone, and shale, and covered with an armor layer of varying thickness. Due to low rock strength and head fall caused by the weirs, rapid scouring downstream of weirs is often observed once the armor layer is worn away. To evaluate weir stability, the shape and depth of scour holes must be identified. The scouring process assumed by existing approaches for estimating the depth of scour holes may not be applicable to weirs in Taiwan. Thus, field geology and scour investigations were conducted at eight sites of diversion weirs located in the western foothills of Taiwan. Based on collected data, three typical categories of 
the scouring process downstream of weirs were identified. The suitability of existing approaches for calculating scour-hole depth on soft rock was also evaluated.

\section{SCOURING PROCESSES DOWNSTREAM OF WEIRS}

Rivers in Taiwan are typically short and steep. The slope of a river channel generally exceeds $1 \%$ in mountainous areas and $0.2-0.5 \%$ on plains. Taiwan receives on average roughly $2,500 \mathrm{~mm}$ of rainfall annually. Heavy rainfall for more than $1000 \mathrm{~mm} /$ hour can occur during typhoons in summer. The runoff amount is also very high due to steep slopes and high rainfall intensity. For example, the watershed of the Chi-Chi Weir is about $2,034 \mathrm{~km}^{2}$, and maximum flow reaches $20,500 \mathrm{~m}^{3} / \mathrm{sec}$ for a 100 -year return period. As flow passes the weir, unit flow rate can reach $160 \mathrm{~m}^{2} / \mathrm{sec}$, and maximum flow velocity can be as high as $19 \mathrm{~m} / \mathrm{sec}$.

The western foothills of Taiwan contain relatively young rock formations, which have low resistance to weathering and erosion by water. Due to the high rainfall intensity, steep slope, and weak geology, the degree of weathering and erosion in watersheds in Taiwan is also very high. Moreover, landslides and debris flows caused by earthquakes and typhoons often occur, contributing to sedimentation of rivers. Monitoring data from the Water Resources Agency, Taiwan, show that the total sediment transport is 3.23 billon tons/year, and the unit sediment transport in many rivers can reach 10,600 tons $/ \mathrm{km}^{2}$, significantly higher than that of most rivers in other countries. These statistical data are also indicative of high river erosion potential in Taiwan.

To investigate scouring processes downstream of weirs, eight typical weirs in the western foothills of Taiwan were studied. Table 1 summarizes the basic data of these weirs. Except for the gravel armor at the Dong-Kou Weir, outcrop rocks at the other seven weir sites are sedimentary rocks. The armor layers at these weirs no longer exist, except for at the Dong-Kou Weir, where thick gravel deposits cover the underlying rock. At the Yi-Shing Weir, bedding planes and two sets of joints are well developed. All outcrops at other weir sites have clear bedding planes without clear joints. Based on the uniaxial compression strength of rock materials, the outcrop rock at the Yi-Shing Weir site can be classified as hard rock; all outcrop rocks at other weir sites are soft rocks. The strike of the rock strata with respect to the flow direction is roughly divided into the following two categories: (1) parallel, which is when the angle between the strike and flow is $<45^{\circ}$; and, (2) perpendicular, which 
when the angle between the strike and flow is $>45^{\circ}$. Flow conditions around scour holes observed in the field are similar to those observed by Lin (2001) in flume tests.

Based on field geology data, site investigations, and erosion patterns of the eight weirs, three categories of scouring processes downstream of weirs were identified, namely, (1) plucking, (2) uniform incision, and (3) trenching incision. These categories are described as follows.

Table 1. Basic data of the studied weirs

\begin{tabular}{|c|c|c|c|c|c|c|}
\hline $\begin{array}{c}\text { Weir } \\
\text { Name }\end{array}$ & $\begin{array}{c}\text { Starting } \\
\text { time of } \\
\text { operation }\end{array}$ & $\begin{array}{c}\text { Height } \\
(\mathrm{m})\end{array}$ & $\begin{array}{c}\text { Length } \\
(\mathrm{m})\end{array}$ & Geomaterial* & $\begin{array}{c}\text { UCS*** } \\
(\mathrm{MPa})\end{array}$ & Orientation. \\
\hline Yi-Sing & 1973 & 25.5 & 100 & Ss & $70-100$ & parallel \\
\hline Hou-Chun & 1983 & 3 & 556.3 & Ss, Sh & $10-20$ & parallel \\
\hline Shih-kang & 1977 & 21.4 & 240 & Ss, Sh & $2-12$ & parallel \\
\hline Chi-Chi & 2001 & 15 & 352.5 & Ss.\&Sh & $5-15$ & parallel \\
\hline Long-Quan & 1982 & 3 & 80 & Sh & $2-30$ & perpendicular \\
\hline Chu-Kou & 1999 & 1.5 & 72 & St with sh & $5-10$ & perpendicular \\
\hline Gia-Sian & 1999 & 7 & 120 & Sh & $10-25$ & perpendicular \\
\hline Dong-Kou & 1973 & 5 & 220.8 & Gravel & - & - \\
\hline
\end{tabular}

*Ss = sandstone; $\mathrm{Sh}=$ shale; $\mathrm{Ss} . \& \mathrm{Sh}=$ alternating layers of sandstone and shale.;

St: Siltstone.

**UCS: Uniaxial compression strength

\section{(1) Plucking:}

The plucking scouring process was observed at the Yi-Sing Weir. This weir is constructed on meta-sandstone with uniaxial compression strength of 70-100 MPa. The outcrop rock has clear bedding planes and two sets of joints. Rock blocks formed by discontinuities exist at this site. Due to the high strength of the sandstone, the rock has high resistance to abrasion. Therefore, plucking of jointed rocks dominates scouring processes. A plunging pool formed due to falling water and blocky rock conditions (Figure 1(a)). Figure 1(b) presents the scouring processes and the shape of the scour hole. This process is similar to that discussed by Bollaert and Schleiss (2003). However, the scour hole appears asymmetrical; the slope in the upstream is gentler than that in the downstream. This differs markedly from that for dams built on hard rocks. Site inspection indicates that scouring depth under the weir foundation was about $7 \mathrm{~m}$. Engineering countermeasures was initiated to mitigate this instability. 
1. Joints were extended by vortex and dynamic water pressure; rock blocks were separated from rock mass by up-lift force.

2. Scour depth under foundation is about $7 \mathrm{~m}$.

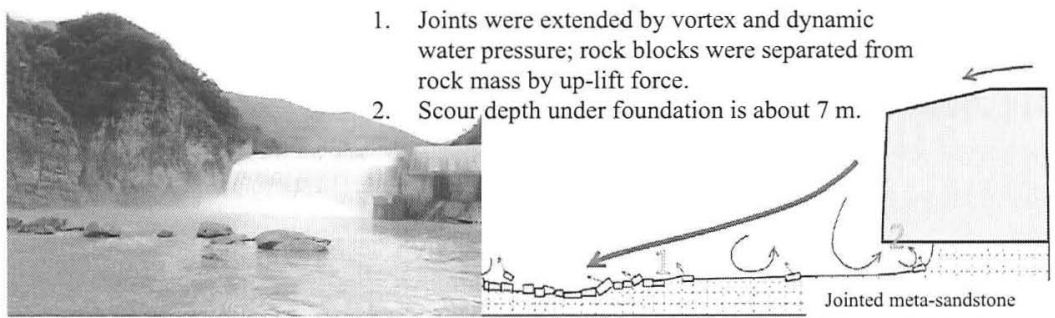

Figure 1. (a) Down-stream view of the Yi-Sing weir: with rock blocks mounding at Down-stream of scour hole.

(b) Illustration of the plucking type of scouring processes.

\section{(2) Uniform Incision:}

The uniform incision scouring process exists at the Long-Quan Weir, Chu-Kou Weir, and Gia-Sian Weir. The rocks at these sites are composed of massive soft sandstone, massive shale, or massive siltstone with thin shale layers. The flow direction is perpendicular to the strike of beddings. Due to the low rock strength and very few joints, abrasion of massive rocks dominates the scouring process. The strength of the soft rock is isotropic; thus, rock abrasion by the flow vortex induced by a jet remains uniform and a circular scour hole is gradually formed. Since the jet impinges a relatively small incline angle relative to the horizontal plane, the slope of scour hole in the upstream is gentler than that in the downstream, which is similar to the case of category 1 (i.e., plucking). If a flow contains large-grain sediments, the scouring rate downstream of weirs increases. Fractures may also develop on rock surfaces when granular sediment impacts rocks. Small-scale plucking scouring may then occur. Figure 2 shows a photograph of the area downstream of the Long-Quan Weir, illustrating the uniform incision scouring process.

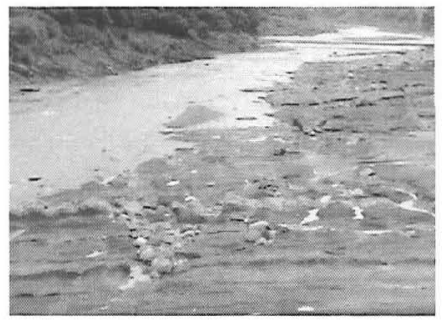

1. The vortex flow induced by jet.

2. Vortex induces the scouring of massive soft rocks gradually.

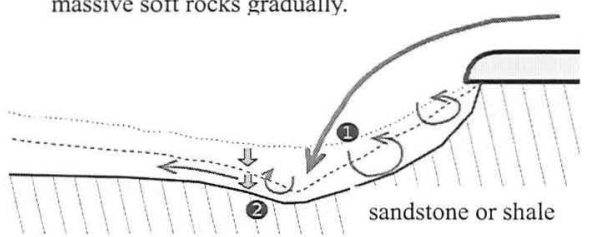

Figure 2. (a) Down-stream view to the Long-Quan weir: uniform scouring process. (b) Illustration of the uniform incision type of scouring process. 


\section{(3) Trenching Incision:}

Trenching incision exists at the Hou-Chun Weir, Shih-kang Weir, and Chi-Chi Weir. Figure 3 shows a photograph downstream of the Hou-Chun Weir, illustrating the cross section perpendicular to flow of the trenching incision scouring process. The rocks at these sites are composed of alternating layers of massive sandstone and thin layers of shale, or alternating layers of massive shale and massive sandstone. The flow direction is parallel to the strike of beddings. Both sandstone and shale are soft rocks. Since the strength and erodibility of alternating thin layers of shale and sandstone is lower than that of massive sandstone, differential abrasion occurs at different layers. The alternating thin layers with low abrasion resistance are eroded faster and flutes at weak layers will develop along the flow direction. Subsequently, fractures developed in massive sandstone due to pressure relief. If rock blocks impact flutes via vortex or flow, the scouring rate increases. Over the long term, a trench along the strike developed.

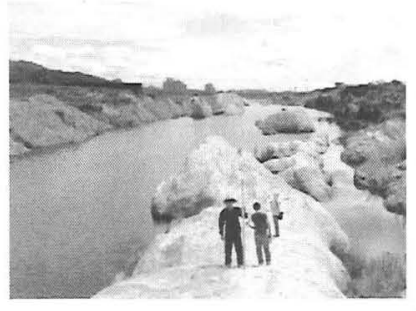

Figure 3. (a)Down-stream view of the Hou-Chun weir: trench was the strike.
1. Flume was developed at low resistant formation along

2. Fractures were developed at higher resistant formation due to pressure relief and rock block formed by vortex.

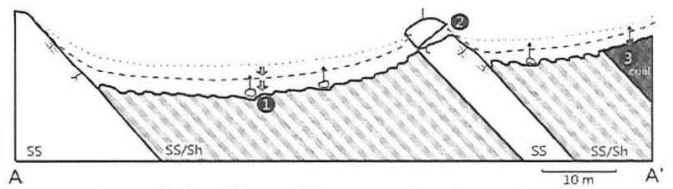
developed along the strike. (b) Illustration of the cross section perpendicular to flow: the Trenching incision type of scouring process.

\section{EVALUATION OF SCOUR-HOLE DEPTH}

The depths of scour holes evaluated by the methods developed by Annandale, et al. and Bollaert and Schleiss were compared with observed data for the Yi-Sin and Chi-Chi weirs to evaluate the suitability of these methods. The two-dimensional numerical program CCHE2D was utilized to calculate hydraulic conditions adjacent to weirs. The CCHE2D model is based on the efficient element method and used the implicit scheme by time stepping to solve continuity equations in each grid (WRA, 2009). Flow rates were chosen for different returning periods. Based on erodibility indices evaluated in field, scour depths at the Chi-Chi and Yi-Sin weirs were 
calculated using the Annandale headcut model and the model developed by Bollaert and Schleiss (2003).

For a known erodibility index, erosion resistance in terms of stream power can be estimated using the Annandale headcut model. Compared with calculated erosive stream power for various elevations of rock beds, one can determine a scour depth at which erosive power is less than erosion resistance in terms of stream power. Using the model developed by Bollaert and Schleiss (2003), scour depth can be estimated based on force equilibrium of rock blocks; the size of a rock block that can be removed by an uplift force can be evaluated, such that scour-hole depth can be estimated. The erodibility index at the Chi-Chi Weir and Yi-Sing Weir was about 600 and 2000 , respectively.

Based on field observations, notable rock scouring occurred at the Chi-Chi Weir during Typhoon Kalmaegi in 2008 , which discharged $10,900 \mathrm{~m}^{3} / \mathrm{s}$ of water flow, corresponding to a return period exceeding 2 years. In this event, a 3-meter scour depth was observed downstream of the Chi-Chi Weir. The scour hole at the Yi-Sing Weir was $15 \mathrm{~m}$ deep and had not yet stabilized. During 2001-2008, this scour hole deepened to $6.2 \mathrm{~m}$, resulted from a maximum discharge of up to $8,527 \mathrm{~m}^{3} / \mathrm{s}$.

Table 2 compares actual and estimated scour-hole depths downstream of the two weirs. The estimated depth of the scour hole at the Chi-Chi Weir by the Annandale model is close to the actual magnitude, but the estimated depth significantly underestimates the magnitude of the scour hole at the Yi-Sing Weir. Conversely, the Bollaert-Schleiss model predicted a similar scour-hole depth at the Yi-Sing Weir, but largely overestimated that at the Chi-Chi Weir. This large difference may be attributed to (1) different mechanical behaviors of soft rock compared to that of brittle rock, (2) different water-jet conditions, and (3) different scouring processes.

Both models were only partially successful and are not generally applicable. The applicability and limitations of both methods warrant further examination.

Table 2 The actual and estimated scouring depths.

\begin{tabular}{|c|c|c|c|}
\hline $\begin{array}{c}\text { Scouring } \\
\text { Depth }\end{array}$ & Actual & $\begin{array}{c}\text { Estimated by } \\
\text { Annandale model }\end{array}$ & $\begin{array}{c}\text { Estimated by } \\
\text { Bollaert-Schleiss model }\end{array}$ \\
\hline Chi-Chi weir & $3 \mathrm{~m}$ & $\sim 3 \mathrm{~m}$ & $23 \mathrm{~m}$ \\
\hline Yi-Sing weir & $15 \mathrm{~m}$ & $1.5 \mathrm{~m}$ & $>15 \mathrm{~m}$ \\
\hline
\end{tabular}




\section{CONCLUSIONS}

Based on data from field geology investigation, site investigations, and scouring pattern recognition for the eight weirs, this study identified three typical categories of scouring process downstream of weirs, namely, (1) plucking, (2) uniform incision, and (3) trenching incision. The plucking scouring process is the dominant process for weirs constructed on jointed hard rocks. The other two processes typical in areas with soft rock. Furthermore, the factors influencing the types of scouring processes were identified; these factors include the type and properties of geo-materials, attitude of discontinuities, density and spacing of discontinuities, and flow conditions. Due to differences in flow conditions, the observed shape of scour holes downstream of weirs, especially for weirs built on soft rocks, differs from that of scour holes downstream of high dams. The scour hole appears asymmetrical; the slope in the upstream is gentler than that in the downstream.

To evaluate the suitability of existing approaches for calculating scour-hole depth on soft rock, the approaches developed by Annandale et al. and Bollaert and Schleiss were used to calculate scour-hole depth at two sites. We conclude that both these methods are only partially successful and are not generally applicable to scouring downstream of a weir on a soft-rock riverbed. This may be attributed to (1) different mechanical behaviors of soft rock, (2) different water-jet conditions, and (3) different scouring processes. Based on the real scouring processes for soft rocks, appropriate methods for scouring evaluation of soft rock, especially for local scouring downstream of a weir, warrant further study.

\section{ACKNOWLEDGMENT}

The authors would like to thank the Water Resources Agency and the National Science Council of the Republic of China, Taiwan, for financially supporting this research.

\section{REFERENCES}

Annandale, G.W. (1995). "Erodibility" Journal of Hydraulic Research. 33(4): 471-494.

Annandale, G.W. (2006). "Scour technology" McGraw-Hill, New York. 430p Bollaert, E. and Schleiss, A. (2003). "Scour of rock due to the impact of 
plunging high velocity jets Part I: A state-of-the art review" Journal of Hydraulic Research. 41(5): 451-464.

Bormann, E and Julien, P.Y. (1991). "Scour downstream of grade-control structures Journal of Hydraulic Engineering, ASCE, 117(5): 579-594.

Fahlbusch, F. E. (1994), "scour on rock riverbeds downstream of large dams" , Hydropower \& Dams, pp.30-32.

Lin, C. (2001)."Prevention of scourng by overflow water or Hydraulic jump in bridge foundation" Proc. Of Conference of Hydraulic Engineering. 202-231 (in Chinese).

Liu ,P .Q. (2005). "A new method for calculating depth of scour pit caused by overflow water jets" Journal of Hydraulic Research. 43(6); 696-701.

Martins, R. (2006). "Contribution to the knowledge on the scour action of free jets on rocky river beds" Proc. the 11th Congress on Large Dams, Madrid, 799-814.

Schoklitsch, A. (1932)." Kolkbildung unter Überfallstrahlen. Die Wasserwirtschart", $341 \mathrm{p}$.

Water Resources Agency. (2009). "A study on the mechanisms and evaluation of rockbed erosion after weir installation (1/2)" (in Chinese).

Whipple, K.X., Snyder, N.P. and Dollenmayer, K. (2000). "Rate and processes of bedrock incision by the upper Ukak river since the 1912 Novarupta ash flow in the valley of Ten Thousand Smokes, Alaska" Geology. 28(9): 835-838. 